Tijana Marković

Univerzitet umetnosti u Beogradu

Fakultet dramskih umetnosti

Katedra za teoriju i istoriju

tijanamarkovic444@gmail.com
УДК 791:314.151.3-054.7(47+57)

https://doi.org/10.18485/slavistika.2021.25.1.15

Оригинални научни рад примљено 13.01.2021.

прихваћено за штампу 17.06.2021.

\title{
FILMSKA REPREZENTACIJA RUSKE EMIGRACIJE NAKON DOBA PERESTROJKE
}

Cilj ovog rada je da na primeru tri filma autora ruskog porekla ispita identitet postsovjetskih emigranata u dijaspori, ali i ruske nacije u vremenu nakon sociopolitičkih i kulturnih promena. $\mathrm{S}$ reformama perestrojke i otvaranjem granica stvaraju se internacionalne koprodukcije i postaju vidljiviji oni autori koji su u nekadašnjem političkom režimu bili skrajnuti ili koji su i sami emigrirali. U tom smislu, primetno je da protagonisti ovih filmova reflektuju različite stavove autora spram novog sistema i talasa emigracija koji je usledio posle perestrojke. Kroz kategorije nostalgije i asimilacije, ovaj rad će pokušati da pokaže da identitet dijaspore nije u potpunosti uniforman i zasnovan na mitskom žalu za otadžbinom, već da se neprestano pregovara između odrednica tamo i ovde, te da je nestabilan baš kao što je takav identitet i same postsovjetske Rusije.

Ključne reči: postsovjetska kinematografija, ruska emigracija, doba perestrojke, akcentovani film.

The aim of this paper is to examine on a sample of three films the identity of the Russian nation and of its diaspora after the period of perestroika. The opening of borders lead to the formation of international coproductions and a growing recognition of authors who had been marginalized by the former regime, as well as of those who had been emigrants themselves. It is apparent that the protagonists of these films reflect diverse attitudes of their authors towards the new regime and the Russian emigration. Through categories of nostalgia and assimilation, this paper will attempt to show that the identity of the diaspora in times of change lacks uniformity and is not rooted in the mythical longing for the homeland, but is rather incessantly being negotiated between here and there and is as unstable as the identity of post-Soviet Russia in the period of perestroika.

Keywords: post-Soviet cinema, Russian emigration, period of perestroika, accented cinema.

U predgovoru svoje knjige European Cinema in Motion Danijela Bergan i Klaudija Sternberg navode da je prethodnih trideset godina evropski film doživeo transformaciju usled sve veće vidljivosti autora koji se bave migracijama, kaoi interesovanja za dinamiku postmodernog multikulturalizma (Berghahn et al. 2010: 2). Migracije u Rusiji su kroz ceo XX vek menjale svoje tokove - od intra- ka intermigracionom kretanju, sa istoka ka zapadu. Sovjetski Savez, iako su u njemu živeli predstavnici različitih nacionalnosti i različitog etničkog porekla, nije širio svoje multikulturalno društvo van granica države. Prema rečima Bridžit Bojmers, mobilnost je bilo moguće ostvariti unutar Sovjetskog Saveza, kretanjem iz sela u grad ili, kao što su činili tražioci političkog azila, odlaskom na zapad (Beumers 2010: 97). Bojmersova u ovom kontekstu navodi da se termin migracija odnosi na kretanja unutar države, dok se svojevoljna ili nasilna napuštanja Sovjetskog Saveza označavaju terminom izgnanstvo - изгнание (Beumers 2010: 98). Pa ipak, kao što navode Danijela Bergan i Klaudija Sternberg, s padom Berlinskog zida i otvaranjem granica 1989. godine, do tada razdvojene sfere Istoka i Zapada bivaju rekonfigurisane, te se postavlja pitanje kakva je priroda nacionalnih identiteta, kao i da li i oni postaju redefinisani brisanjem granica. 
Promene koje su usledile kao posledica raspada Sovjetskog Saveza i otvaranja njegovih granica, svoju reprezentaciju dobijaju u filmovima brojnih autora. Međutim, identitetski status emigranta ili izgnanika - kao filmskog protagoniste ili autora - možda je najkompleksniji. Slika postsovjetske Rusije ogleda se u dijaspori i njenim pripadnicima, koji, prema rečima Hamida Nafisija, svojevoljno napuštaju zemlju porekla, s kojom održavaju ambivalentne veze - iako ostaju u tuđini, imaju snažnu želju za povratkom, koja je centralna nit „akcentovanog filma” (Naficy 2001: 12). Hodajući na granici između ovde i tamo, onda i sada, emigrantski identitet se obrazuje u liminalnom prostoru, a kategorije jezika i nostalgije su stožeri u okviru kojih se identitet određuje.

Ovaj rad će se stoga baviti filmovima čija je centralna tema život ruskih emigranata u postsovjetskom dobu, koje dolazi nakon ,glasnosti” i „perestrojke”. Filmovi Prozor и Pariz (Окно в Париж, 1993, Jurij Mamin), Interdevojka (Интердевочка, 1989, Petar Todorovski) i Janini prijatelji (Ha-Chaverim Shel Yana, 1999, Arik Kaplun $)^{1}$ bave se životom ruskih emigranata u razvijenim zemljama Zapadne Evrope i Izraelu. Kroz guste slojeve različitih kultura, istorija, religija, statusa, polova, seksualnosti i, naposletku jezika, oni pokušavaju da pronađu svoje mesto u društvu. Stoga, ovaj rad će pokušati da ilustruje kako se portret emigranta konstruiše kroz kategorije nostalgije za otadžbinom i procesa asimilacije u novu sredinu. $\mathrm{U}$ tom smislu, u trenutku kada autori dobijaju veće slobode u nacionalnim produkcijama, a internacionalne koprodukcije bivaju omogućene otvaranjem granica, ovi filmovi prvi put predstavljaju viziju onih autora čiji se glasovi do tada nisu čuli, ali i daju uvid u to kako Rusija izgleda iz ugla onih koji je posmatraju sa strane.

\section{Ruski autori i kulturna reforma perestrojke}

Izraelska teoretičarka filma Olga Geršenson navodi da je stereotipni portret ruskih emigranata počeo da se menja onog trenutka kada su filmski autori koji su i sami emigrirali počeli da stvaraju. Prema njenim rečima, baš su oni bacili novo svetlo na autentičnu reprezentaciju zemlje porekla svojim ,akcentovnim” jezikom (Gershenson 2011: 33). S druge strane, različita viđenja Rusije manifestovana kroz film omogućena su i otvaranjem tržišta, kao i sve većim brojem međunarodnih koprodukcija u kojima filmski radnici različitih nacionalnosti sagledavaju savremenu Rusiju iz svojih identitetskih polja. Ali, i jednima i drugima je zajedničko ispredanje narativa i otvaranje tema koje do tada nije bilo moguće ni zamisliti u sovjetskoj kinematografiji.

Kinematografija za vreme perestrojke i posle njega - sasvim sigurno - ima značajno mesto u istoriji ruskog i sovjetskog filma. Horton i Brašinski navode da termin perestrojka označava stanje promene i rekonstrukcije, pri čemu promene u politici, kulturi i filmu koje počinju 1985. godine treba posmatrati kao proces, a ne kao rezultat (Horton, Brashinsky 1992: 4). Prema njihovom tumačenju, ruska kinematografija s kraja osamdesetih godina XX veka doživljava oštar zaokret kada u korpus filmova ujedinjenih totalitarnom socijalističkom ideologijom probija novi

\footnotetext{
${ }^{1}$ Iako snimljeni za vreme (Interdevojka) i nakon perestrojke (Prozor u Pariz i Janini prijatelji), ovi filmovi spadaju u istu grupu filmova, koji usled kulturne reforme, bivaju oslobođeni starih tabua, te otvaraju nove do tada skrajnute teme.
} 
talas ruskog filma koji upravo teži suprotnom - polifoniji neretko suprotstavljenih glasova. Sovjetski umetnici, do tada izolovani od svetskog kulturnog mejnstrima, sada dobijaju mogućnost da svoje ideje plasiraju na stranim platnima, te se kao jasno pitanje postavlja: da li ostati u zemlji koju Horton i Brašinski u dovitljivoj sintagmi nazivaju „sedamdesetogodišnjim novorođenčetom koje je potrebno regenerisati”, ili otići u ,slobodu”, koja je toliko dugo čekala iza zatvorenih vrata (Horton Brashinsky 1992: 5).

U filmovima Jurija Mamina, Petra Todorovskog i Arika Kapluna prepoznaju se različiti pristupi temi odlaska i ostanka s kojom se autori suočavaju. Jurij Mamin je primer autora koji zbog svoje antikomunističke ideologije počinje svoju filmsku karijeru tek po uspostavljanju perestrojke i dolaskom Mihaila Gorbačova na vlast. Kao što je i očekivano, Maminovi likovi većinom i jesu građani koji se bore za socijalnu pravdu, čije patnje izaziva upravo trulost sistema - socijalističkog, a kasnije i kapitalističkog. Jurij Mamin, uprkos otporu koji je, nakon Gorbačova, vlast ponovo imala prema njemu, pripada autorima koji su ostali da stvaraju u Rusiji, koristeći otvaranje granica za uspostavljanje međunarodnih koprodukcija. Film Prozor u Pariz rezultat je upravo rusko-francuske koprodukcije, koja je omogućila distribuciju filma u SAD, ali i plasman na festivale među kojima je i Berlinski filmski festival.

Nasuprot njemu, Petar Todorovski je uživao veliku popularnost u Sovjetskom Savezu i pre perestrojke, pa Ana Loton zaslugu za to vidi u nepretencioznom tonu duhovitih melodrama s kojima je Todorovski počeo svoju filmsku karijeru (Lawton 2002: 70). Todorovski, kao režiser koji je ceo radni vek proveo u Rusiji, ne spada ni u kategoriju emigranta, ni izgnanika, pa je uprkos tome film o emigrantkinji Tanji zaokret u njegovoj karijeri. Prostitucija kao centralna tema nije bila česta u sovjetskoj kinematografiji, kao ni sporedne teme poput crnog tržišta, alkoholizma i suicida (Lawton 2002: 279). Iako Todorovski ostaje u ključu pseudorealistične melodrame, vidan je uticaj novih tendencija ka tabu temama koje se javljaju kao rezultat politike glasnosti. Za razliku od Mamina, koji kroz svoj film provlači snažnu poruku o važnosti ostanka u Rusiji uprkos trulom socioekonomskom i političkom stanju, ali i o saradnji s „komšijama”, Todorovski kroz lik Tanje u potpunosti odbacuje Zapad i njegove vrednosti birajući povratak „majci Rusiji”, koja i pored svih problema ostaje superiorna.

$\mathrm{Na}$ kraju, Arik Kaplun predstavlja kategoriju autora „akcentovanog filma” koji su svoj rad nastavili van ruskih granica. Kaplun, režiser jevrejskog porekla, nakon završene filmske škole u Izraelu snima film Janini prijatelji u izraelskoj produkciji, s ruskom glumicom Evelinom Kaplun. Interesantno je i da postsovjetski, i izraelski film devedesetih godina teže izgradnji jedinstvenog identiteta nacije kroz filmsku reprezentaciju. U slučaju ruskog filma, Bridžit Bojmers navodi da nakon raspada Sovjetskog Saveza, a početkom devedesetih godina, nastaje potreba za reafirmisanjem identiteta Rusije kao svetske sile kroz nostalgiju - oživljavanjem zlatnog doba šezdesetih i sedamdesetih godina, ali i vraćanjem predrevolucionarnom dobu (Beumers 2010: 99). Slično tome, izraelska kinematografija je od šezdesetih godina usmerena ka izgradnji homogenog nacionalnog identiteta, pri čemu je na filmskom platnu primetna potpuna asimilacija emigranata (Gershenson 2011). Međutim, Kaplunov film ne pripada ni jednoj ni drugoj ideološkoj strani, već se može svrstati u kategoriju „etničkog” filma, koji dovodi u pitanje sam pojam identiteta (Naficy 2001: 15). Za razliku od filmova Todorovskog i Mamina, u kojima 
su nacionalne pripadnosti i osećanja spram njih jasno definisana, Kaplun identitetsko pitanje anulira kroz besmisao rata i savremene probleme koji se javljaju uvek i svuda bez obzira na granice.

\section{Emigranti i nostalgija}

Svetlana Bojm definiše pojam nostalgija kao čežnju za domom koji više ne postoji ili čak nikada nije ni postojao - nostalgija je osećanje gubitka i nepripadanja (Boym 2001: 13). Ona navodi da nostalgija u biti nije čežnja za prostorom kao takvim, već za vremenom mladosti pojedinca, te $u$ tom smislu nostalgija briše istoriju i pretvara je $u$ ličnu ili kolektivnu mitologiju (Boym 2001). U filmovima izabranim za ovu analizu nostalgično osećanje povezano je sa specifičnim trenutkom u kojem se našla Rusija, te u svakom portretu emigranta možemo pronaći čežnju za prošlim vremenom pre nego za konkretnim mestom (Beumers 2010: 96).

Maminov film Prozor u Pariz govori o liminalnom prostoru između jedne mansarde i grada, između starog i novog sistema, Sankt Peterburga i Pariza, ostajanja i odlaženja, svakodnevnog života i sna. Protagonista Kolja, nastavnik muzičkog vaspitanja u osnovnoj školi, muzikom i umetnošću hipnotiše decu ograničenu sistemom savremenog obrazovanja svedenog na biznis-proračune. Prozor u svet umetnosti ostvaruje vizuelnu reprezentaciju kroz otkrivanje pravog, do tada zapečaćenog prozora, čijim otvaranjem stanovnici starog komunalnog stana mogu da zakorače u Pariz. Sagledavanjem oba grada i oba sistema Kolja uviđa da su sve mane nove Rusije - kapitalistički sistem i sve veće duhovno i materijalno siromaštvo - učinile da fantazam nekadašnje ruske imperije u mislima stanovnika Sankt Peterburga postane utočište od trenutnih nedaća. Uprkos tome što Kolja kroz film prkosi sistemu, ne pristajući da se povinuje poništavanju svih vrednosti zarad pukog preživljavanja, kraj filma šalje neočekivanu poruku koja reflektuje stavove i karijeru samog Jurija Mamina. Iako je „prozor” otvoren, Kolja - razočaran onim što predstavlja današnji Zapad, odlučuje da ostane u svom gradu. U govoru koji održi svojim učenicima nakon njihovog insistiranja da ostanu u Parizu, nalazimo primer supkategorije nostalgije koju Svetlana Bojm naziva restorativna nostalgija. Ova vrsta utopističke nostalgije odnosi se na ideju o tome da će dijaspora ponovo izgraditi izgubljeni dom (Boym 2001: 41-55), pri čemu dijasporu na primeru filma čine deca kao predstavnici nove generacije okupljene oko Kolje. Kao i Kolja, i Mamin, uprkos zabranama i ideološkim neslaganjima, ostaje u Rusiji, gde tri decenije gradi svoju karijeru. Pa ipak, interesantan je i suprotan primer nostalgije koju Bojmova naziva reflektivnom nostalgijom i koja se odnosi na sećanje i čežnju za idealnom otadžbinom (Boym 2001: 41). Jedan od Koljinih ruskih poznanika, dobrostojeći pijanista u Parizu, nakon tugaljivih vapaja za Rusijom, komunalnim stanom i Nevskim prospektom, za koji bi „dao sve ono što je stekao”, našavši se na istom tom Nevskom prospektu, bez razmišljanja „daje sve" ne bi li se opet vratio u surovi Pariz. Iz ova dva primera može se zaključiti da je povratak, odnosno odlazak, veoma težak $i$ da je nemogućnost promene trenutnog stanja uslovljena nekim vidom nostalgije. U tom kontekstu Danijela Bergan naglašava da su mit o „slavnom povratku” i njegova različita interpretacija neke od distinktivnih odlika migrantskog filma (Berghan 2013: 58). 
Sličnu rastrzanost između tamo i ovde vidimo i u liku Tanje, protagonistkinje filma Interdevojka. Endru Horton zapaža da je Tanja „,polifonija kontradikcija” ona je dobra devojka danju, a loša noću, nju luksuz privlači, ali istovremeno i odbija (Horton, Brashinsky 1992: 119), pa kao i pijanista iz filma Prozor u Pariz, u trenutku kada ode na Zapad, u duhu reflektivne nostalgije, počinje da čezne za Istokom. Tanjino napredovanje na društvenoj lestvici, koje prividno otvara mogućnost povratka, istovremeno je i sve više koči, što i jeste u skladu s tumačenjem Klaudije Bergan - prva generacija emigranata nikada ne skida kofer sa ormana, koji stoji spreman da se jednoga dana s njime vrate (Berghahn 2013: 58). Tanjin nestabilni identitet pronalazi mir u projekciji stabilnog seta vrednosti na figuru „majke” kojoj želi da se vrati, pre svega u trenucima dosade, neuklapanja u zapadnjački način života i krajnje usamljenosti. Uloga mitoloških predstava u kreiranju identiteta nije nešto što primećujemo samo na ličnom već u velikoj meri i na nacionalnom planu, pre svega u teškim vremenima. U vreme raspada Sovjetskog Saveza, kada je „sovjetski identitet nestao, a ruski je trebalo izgraditi” (Beumers 2010: 99), i teškog ekonomskog stanja, ruska kinematografija pribegava promovisanju snažnih nacionalnih vrednosti kojima se, prema rečima Bridžit Bojmers, evociraju slavna sovjetska imperija i predrevolucionarna epoha (Beumers 2010: 100) kako bi se publici pružilo prividno olakšanje.

U ruskim filmovima migrantske tematike nostalgija vrlo često ima simboličku reprezentaciju u narodnim pesmama, poeziji ili predmetima koje emigranti nose sa sobom. I Tanjin i Koljin identitet ima uporište u muzici. Kroz ceo film Prozor $u$ Pariz provlači se simbol klavira i klasične muzike. Suočen sa susedima, koji igrom slučaja rade upravo u fabrici klavira, a prema instrumentima i visokoj kulturi se odnose krajnje nezainteresovano, Kolja muzikom i umetnošću pokušava da dopre do dece koja polako postaju roboti surovog sistema. Sa druge strane, scena napuštanja Rusije, kao i finalni trenutak filma Interdevojka, uobličeni su u nostalgičnoj ruskoj narodnoj pesmi o lutalici koji prelazi Bajkalsko jezero da bi video svoju majku. Dok pevuši, pošto saznaje za smrt svoje majke, Tanja doživljava saobraćajnu nesreću, čime nemogućnost povratka kući postaje konačna.

Arik Kaplun vidi nostalgiju na drugačiji način. Cilj ruskih emigranata u Izraelu jeste snalaženje, osiguravanje finansijske sigurnosti i prevazilaženje dnevnih peripetija. U tom duhu nostalgija je samo sredstvo dolaženja do lakog novca, kao što je slučaj u priči o bračnom paru koji u Izrael dovodi starog vojnog veterana, čija su uniforma i ratna odlikovanja isključivo u funkciji prošenja na ulici. U obračunu između Alika, koji rukovodi idejom ovakve vrste zarade, i ruskog harmonikaša, koji ne želi da deli profit s novim stanovnikom trotoara, vidimo dvojicu ruskih emigranata koji ni u jednom trenutku ne pokazuju nostalgiju za otadžbinom niti razvijaju duh ujedinjene dijaspore koja potvrđuje identitet kroz zajednička patriotska osećanja. Kada shvate da u Izraelu neće zaraditi veliki novac, članovi ove porodice odlučuju da krenu u Ameriku, s novom parolom na prosjačkom šeširu: Pomozite ratnom heroju da se vrati u Rusiju. U tom smislu sva predanja i simbolika koja prati mit o „majci Rusiji” reprezentovana kroz narodne pesme harmonikaša ili ordenje starog čoveka, postaju univerzalna karta igranja na patriotska osećanja publike širom sveta. Vrlo je interesantno da u filmu u čijem su središtu Rusija i Izrael, dve države sa izraženim nacionalnim diskursom, ideologija biva izostavljena, a u prvi plan se stavlja globalno 
stanje nemira i ratova, kao i lakonična poruka da je za srećan život presudna identifikacija sa srodnom dušom, a ne nacijom.

\section{(Ne)mogućnost asimilacije}

Nakon raspada Sovjetskog Saveza dolazi do masovnih emigracija iz Rusije, naročito u Nemačku, Izrael i SAD (Heleniak 2001: 535). U tom smislu masovne migracije i stvaranje novih dijaspora menjali su kulturu i umetnost zemalja domaćina. Olga Geršenson daje primer ruske dijaspore u Izraelu, koja je devedesetih godina postala vrlo česta tema u izraelskoj kinematografiji, između ostalog i zbog ruskoizraelskih filmskih koprodukcija (Gershenson 2011). Zato je vrlo važno ispitati stepen asimilacije emigranata u novu sredinu, jer došavši u novu zemlju, oni transformišu ne samo kulturu oko sebe već i sami sebe.

U razmatranju asimilacije vrlo značajnu ulogu ima i jezik. Kao prva odrednica identiteta, jezik učestvuje u karakterizaciji likova, ali njegov izbor daje i informaciju o stavovima autora prema identitetskim pitanjima emigranata. Olga Geršenson navodi primer ruskih filmova u kojima je hebrejski dominantan jezik, čak i kada su protagonisti ruskog porekla, što je strategija primenjivana zarad pridobijanja većeg broja izraelskih mejnstrim gledalaca, ali i zarad osnaživanja jedinstvenog hebrejskog identiteta kroz apsolutnu asimilaciju (Gershenson 2011: 31). Međutim, u filmu Janini prijatelji, u čijem su središtu likovi ruskog porekla, ovakav jezički model ne postoji, te je sam narativ oslobođen reduktivnog principa potpune asimilacije. Odnos hebrejskog i ruskog vrlo je realistično prikazan - u svakodnevnim situacijama likovi u svojim nacionalnim grupama komuniciraju na svom maternjem jeziku. Do preključivanja kodova dolazi samo kada to nalažu odnosi moći - odnos Jane i gazdarice stana koji iznajmljuje podrazumeva da je jezik komunikacije hebrejski, što primećujemo i u odnosu sa Elijem, budući da je hebrejski jedini zajednički kod. Lik Jane u potpunosti odgovara standardu reprezentovanja ruske emigrantkinje u Izraelu - lepa, mlada, bespomoćna žena sa izrazito slovenskim crtama lica, do čije asimilacije, prema rečima Olge Geršenson, dolazi isključivo kroz romantičnu vezu sa Izraelcem (Gershenson 2011: 32). Međutim, Arik Kaplun subverzivno pristupa ovom stereotipu, time što je i sâm Eli na određeni način otuđen od izraelske zajednice. On provodi vreme u svetu video-snimaka ljudi i događaja koje beleži na traci, dok sanja da ode u Ameriku i upiše filmsku režiju. Ovakav nedostatak patriotskih osećanja automatski pozicionira Elija i Janu izvan standardnog narativa ljubavnog odnosa u funkciji kreiranja ideologija. U liku Elija možemo prepoznati biografiju samog autora koji napušta Rusiju i odlazi u Izrael, gde završava filmsku školu, ali u svojim filmovima zadržava rusku tematiku, što ukazuje na to da do potpune asimilacije njegovog filmskog stvaralaštva nije došlo. Stoga, i Eli i Jana jesu primer savremenih mladih ljudi koji migriraju iz države u državu, učeći jezik, poštujući običaje države u koju dolaze, ali zauvek izmičući jasnoj nacionalnoj identifikaciji.

S druge strane, filmovi Prozor u Pariz i Interdevojka prikazuju potpunu nemogućnost asimilacije. Nakon otkrivanja „prozora”, Koljine komšije odlaze u Pariz i izvodeći ruske nacionalne igre, ali i obmanjujući publiku, pokušavaju da zarade novac. Iako u Parizu nailaze na izobilje i raskoš na koje u Sovjetskom Savezu nisu navikli, oni se tome ne pokoravaju, uz opaske da su Rusi „200 godina branili 
Francuze i oplodili francusku kulturu”. Ruski sociolog Lav Gutkov ovo definiše kroz kompleks žrtve kojom nacija dokazuje svoju superiornost, ujedno se štiteći od bilo kakvog delovanja i preuzimanja odgovornosti (Gudkov 2004). Gutkov navodi da je status žrtve karakterističan za ruske filmske likove, koji njime opravdavaju svoju pasivnost (Gudkov 2004: 108). S druge strane, Francuskinja Nikol koja živi u susednom stanu biva zaprepašćena bedom i siromaštvom kada se igrom slučaja nađe u Sankt Peterburgu - tada postaje jasno da je asimilacija za obe strane nemoguća. U sukobima izbeđu Rusa i Francuskinje, svaka strana govori svoj jezik, a intenzitet tona raste zajedno s međusobnim sociokulturnim nerazumevanjem. Jedino u liku Kolje vidimo napor da se prevaziđu barijere - on pokušava da se sporazume s Nikol učeći par reči francuskog, tražeći posao u Parizu, i uživajući u francuskoj kulturi. Međutim, odabravši da se ipak vrati u svoj grad, ali i da nakon zatvaranja starog probije novi prozor u Pariz zarad obnavljanja ljubavi s Nikol, Koljina asimilacija postaje ono što Olga Geršenson naziva nepotpunom asimilacijom u kojoj pojedinac vaga između dva nacionalna identiteta kroz kompleksne i često teške procese (Gershenson 2009: 22). Kolja je duboko razočaran u oba sistema, ali istovremeno nastoji da prevaziđe teškoće i unapredi međuljudske odnose.

Konačno, lik Tanje u filmu Interdevojka spada u kategoriju junakinja kojima se iskazuje da je i nakon prelaska granice kulturni jaz nemoguće premostiti jer emigrant ne pronalazi svoje mesto ni ovde - ni tamo. Tanja je stereotip ruske emigrantkinje - ona je noću prostitutka, a danju medicinska sestra koja sanja o boljem životu na Zapadu. Međutim, kada konačno ode u Švedsku, uz pomoć klijenta koji postaje njen muž, glorifikaciju Zapada zamenjuje glorifikacija Rusije. Materijalna stabilnost nije dovoljan faktor koji bi Tanji obezebedio mesto u švedskom visokom društvu, te je asimilacija konstantno sabotirana njenom prošlošću, jezičkom barijerom, ali i kulturološkim razlikama, na kojima, kada shvati da nikada neće postati deo društva, Tanja još više insistira. Olga Geršenson navodi primer da se ruski emigranti, vrlo često pripadnici marginalizovanih društvenih grupa, okreću mitu o velikoj Rusiji iz prošlosti, te njihovu nostalguju opisuje kao romantično fantaziranje o naciji (Gershenson 2009: 33). Tanjin lik takođe otvara i pitanje uloge roda u procesu asimilacije. U tom kontekstu, Dafina Lemiš navodi da se emigrantkinje suočavaju s dvostrukom stigmatizacijom jer su istovremeno i žene i migranti (Lemish 200: 334). Za ručkom koji njen suprug priređuje za svoje kolege, Tanja je stavljena u poziciju seksualnog objekta - muškarci, ali i neke žene, komentarišu njen izgled i neposrednost isključivo kao refleksiju njene prošlosti i ruske nacionalnosti. To kulminira scenom u kojoj jedan od gostiju seksualno napastvuje Tanju u njenoj sobi, posle čega ga ona u samoodbrani udara puškom i zamalo da ga ubija, što je jedan od retkih trenutaka u filmu u kojem se odnosi moći menjaju, a Tanja fizičkim nasiljem ruši stigmu da je bespomoćna prostitutka. Pa ipak, nesrećan kraj filma govori da je pred ruskim emigrantima dug put prevazilaženja predrasuda i potpune (svojevoljne) asimilacije.

\section{Zaključna razmatranja}

U ovom radu analizirana su tri filma u kojima se razmatra pozicija Rusije krajem osamdesetih i početkom devedesetih godina XX veka kroz položaj ruskih emigranata u dijaspori. U filmovima Prozor u Pariz, Interdevojka i Janini prijatelji protagonisti dobijaju šansu da odu na Zapad, o kojem su uvek maštali. Iako svi doživljavaju 
razočaranje u novoj sredini, ono što ih razlikuje je razrešenje odnosa s prošlošću. U filmu Prozor u Pariz autor Jurij Mamin kroz lik Kolje iznosi ideju da je prošlost, baš kao i sadašnjost, daleko od one idealizovane koja izaziva emigrantsku nostalgiju. Rečima ,ranije ste stvarali graditelje komunizma, a sada kapitalizma”, Kolja naglašava da je ideja velike Rusije iluzija, a da jedini progres leži u obrazovanju nacije i obnovi kulture i umetnosti kao vrhovnih vrednosti, što je zadatak koji ruska dijaspora treba da sprovede u delo. Sa druge strane, u filmu Interdevojka asimilacija u novo društvo nije moguća zbog kulturnih barijera, ali isto tako nije moguć ni povratak, te stoga ovaj film migrantsko putovanje vidi kao unapred osuđeno na propast. Bojmersova navodi da su emigranti često prikazani na filmu kao usamljene, otuđene figure, žrtve društva koje im ostaje nedostupno, bilo zbog toga što ne žele da mu se prilagode, bilo zbog toga što bivaju marginalizovani (Beumers 2010: 111). Na kraju, film Janini prijatelji nosi potpuno drugačiju poruku: dijaspora više nije stožer jedinstvanog identiteta $-u$ kolu globalizacije, država odabrana za život jeste ona u kojoj su finansijske prilike najbolje ili u kojoj se ostvaruje ljubavni odnos. Ukoliko je nešto od ovih prioriteta narušeno, emigranti nastavljaju dalje da tragaju za novim mestom, pri čemu identitet biva zamagljen različitim granicama, jezicima i nacionalnostima.

Ono što je pak zajedničko ovim filmovima, ali i ono što provejava u ruskoj kinematografiji pre i posle promene političkih režima, jeste portret ruskog emigranta kao usamljenika koji pati. Međutim, razlozi ove patnje su raznoliki; patnja može biti za izgubljenom zemljom, vrednostima, ljubavlju ili vremenom. Činjenica da s novim vremenom dolaze i novi problemi s kojima se emigranti susreću, te da reprezentacija nostalgije nije više u potpunosti okrenuta ka čežnji za „velikom Rusijom” i ,ruskom dušom", ukazuje na to da celokupan savremeni ruski identitet nije jednostavno smestiti u poznate kategorije prisutne u kinematografiji. U tom smislu, istraživanje stavova pripadnika sadašnje ruske dijaspore, ali i filmova autora koji su i sami iseljenici, predstavlja početnu tačku za redefinisanje odnosa spram pojma „bivanje Rusom" u današnjoj kinematografiji.

\section{Citirana literatura}

Beumers, Brigit. "Nostalgic Journeys in the Post-Soviet Cinema“. [In:] D. Berghahn, C. Sternberg (eds.) EuropeanCinema in Motion. London: Palgrave MacMillan, 2010, 96-113.

Berghahn, Daniela, Claudia Sternberg (eds.). European Cinema in Motion: Migrant and Diasporic Film in Contemporary Europe. London: Palgrave MacMillan, 2010.

Berghahn, Daniela. Far Flung Families. Edinburgh: Edinburgh University Press, 2013.

Boym, Svetlana. The Future of Nostalgia. New York: Basic Books, 2001.

Brashinsky, Michael, Andrew Horton. The Zero Hour: Glasnost and Soviet Cinema in Transition. Princeton: Princeton UP, 1992.

Gershenson, Olga. "Accented memory: Russian immigrants reimagine the Israeli past". The Journal of Israeli History 28 (1), 2009: 21-36.

Gershenson, Olga. "Aliyah to the Movies: Russian \& Israeli Cinema". Jewish Quarterly 58/1, 2011: 31-36. 
Heleniak, Timothy. "Migration and restructuring in post-Soviet Russia“. Demokratizatsiya 9/4, 2001: 531-549.

Lawton, Anna. Before the Fall: Soviet Cinema in the Gorbachev Years. Bloomington: Xlibris Corporation, 2002.

Lemish, Dafna. "The Whore and the Other: Israeli Images of Female Immigrants from the Former USSR“. Gender \& Society 14/2, 2000: 333-349.

Naficy, Hamid. An Accented Cinema: Exilic and Diasporic Filmmaking. Oxford: Princeton University Press, 2001.

\title{
Tijana Marković
}

\section{THE CINEMATIC REPRESENTATION OF RUSSIAN EMIGRATON AFTER THE PERIOD OF PERESTROIKA}

\begin{abstract}
Summary
The transitional period of perestroika (1985-1991) brought about significant socio-political and cultural changes, and therefore a transformation of Russian cinema. This paper reflects on the newlyformed national identity through characters of emigrants, who struggle to balance between cultural patterns of the East and the West, between the old and the new homeland. Fleeing the system or rebuilding it - what were the consequences of the newly gained liberties? The authors of the films Окно в Париж (Y. Mamin, 1993), Интердевочка (P. Todorovsky, 1989) and Ha-Chaverim Shel Yana (A. Kaplun, 1999) analysed in this paper have opposing views on this question. Regarding the category of assimilation, both Mamin and Todorovsky conclude that it is quite difficult if not completely impossible for Russians to become part of the new society, while Kaplun sees postSoviet emigrants as free citizens of the world who are not led by nostalgia, but by love and financial interests. Finally, it is important to note that these films are directly reflective of the authors' careers as well as their attitudes towards identity - the plurality of their voices offering a new perspective on the topics of (alie)nation, unity and what it means to be a Russian in the new era of history.
\end{abstract}

Keywords: post-Soviet cinema, period of perestroika, accented cinema, Russian emigration. 